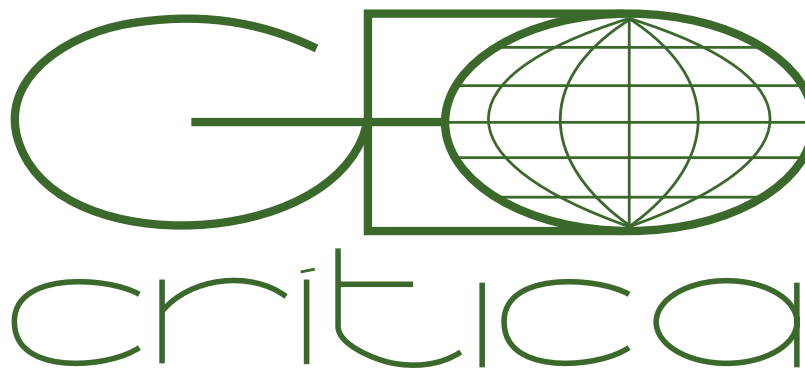

Revista Electrónica de Geografía y Ciencias Sociales Universitat de Barcelona

\title{
PRODUCCIÓN DE ESPACIO EN LA EXPANSIÓN NEOLIBERAL EN MADRID
}

\author{
Daniel Morcillo Álvarez \\ Universidad Politécnica de Madrida \\ danuda@movistar.es
}

Recibido: 15 de enero de 2017. Aceptado: 15 de junio de 2017

\begin{abstract}
Producción de espacio en la expansión neoliberal en Madrid (Resumen)
Tras dos décadas de expansión neoliberal, la crisis iniciada en 2007 parece haber puesto en entredicho la forma de producir la ciudad y los niveles de competencia espacial que estaban dándose, en especial entre el centro y la periferia urbanas. La atención puesta en las consecuencias que sobre el soporte físico y morfológico se producía en las periferias, relegó el estudio de los centros urbanos, de su desarrollo y de su papel en la producción neoliberal de espacio. Por ello, parece pertinente preguntarse qué estaba ocurriendo en ellos, en concreto en la Almendra Central de Madrid, mientras se daba la expansión de la periferia. El análisis morfológico de las geografías de acumulación de capital, económico, simbólico y social, nos aventura una intensificación de los valores de elitización y competencia durante los años previos a la crisis, aparentemente consolidados en el discurso urbano actual.
\end{abstract}

Palabras clave: Producción de espacio, posición social, centralidad urbana, inversión pública, neoliberalismo

\section{Space production in the neoliberal expansion in Madrid (Abstract)}

After two decades of neoliberal expansion, in 2007 begins a global crisis that also manifests the crisis of space production in the cities and the levels of spatial competition, especially between urban centres and urban suburbs. The studies were focused over the urban forms and social morphology that were produced in suburbs, so, in fact, the studies about urban center, their develop and their place in the neoliberal production of space have been relegated. So, we think it is important to ask us about what was happened in urban centers in these years, particularly in the Almendra Central of Madrid. While suburbs in Madrid were growing up, there were several changes in its central areas.. One kind of analysis, focused on morphology of capital accumulation system — symbolic, economic and social-, should tell us the intensification of elitization and competitive values rose along the years before the recession, that were consolidated inside the current urban discourse.

Key words: Space production, social position, urban center, public investment, neoliberalism 
Desde el último tercio del siglo XX, la fase neoliberal del capitalismo ha ido desarrollándose a partir de la consideración de la desregulación de las relaciones económicas, sociales y cotidianas, lo que se ha concretado en la economía de mercado, la privatización de los servicios sociales y una creciente financiarización de la sociedad. La aspiración neoliberal de una sociedad igualitarista tiene su fundamentación en la hegemonía de una clase media cuyo acceso a la riqueza global se llevaría a cabo por su acceso al consumo. Esta aspiración queda supeditada a una reorganización de todo el espacio social, y tal y como avanzara Lefebvre ${ }^{1}$, iría pareja a una urbanización completa de la sociedad. Sin embargo, el igualitarismo parece haberse convertido en una frustración colectiva al observar cómo no sólo no ha sido posible sino que aparece como una gran ficción, entre grandes desigualdades, una creciente polarización de la riqueza, un fuerte desequilibrio urbano - tanto en el territorio como en el interior de las ciudades-y una intensificación de la competencia en todos sus aspectos, esto es entre organizaciones, individuos y, por supuesto, espacios.

El esfuerzo realizado por las clases subalternas por alcanzar el bienestar prometido, se ha traducido en una desposesión en términos económicos, culturales y simbólicos. La diferenciación espacial parece servir, en la lógica neoliberal, para limitar el acceso a bienes y servicios pero también, por otro lado, para contener o suprimir derechos adquiridos en la fase de producción fordista. Es por ello que esta situación nos sugiere que se ha ido consolidando un nuevo modelo de coerción, basado en una dominación asimilada que tiene su razón de ser en el discurso del ascenso social y en donde se intuye un papel esencial del espacio como soporte físico de las relaciones de reproducción social.

Sin duda, la interconexión entre el espacio social y el marco físico está en el origen de la ciudad, pero no adquiere dimensiones relevantes hasta el proceso de industrialización capitalista, que, según apunta Lefebvre ${ }^{2}$, consigue imbricar la reproducción biológica, la de la fuerza de trabajo y la de las relaciones de producción. Sin embargo, la globalización, y más recientemente la fase neoliberal, ha roto esta interrelación en favor de la reproducción de capital, algo que vendría determinado por la reorganización espacial a la que apunta Brenner ${ }^{3}$ dentro de un proceso mas amplio de reorganización del capitalismo. Este concretaría un cambio en las formas de producción, a través de un incremento del sector financiero. La búsqueda de la reproducción de capital sin producción material se vislumbra en la interrelación de los sectores financiero e inmobiliario. La resultante es la expansión de la urbanización y la reconversión de ámbitos urbanos bajo una lógica de destrucción creativa del espacio.

Expansión y reconversión urbana son rasgos una solución por infraestructuras, según la cual el capitalismo buscaría reproducir capital produciendo espacio con la finalidad de fijar excedentes, pero llevando irremediablemente a un nuevo punto

1 Lefebvre, 2013

2 Lefebvre, 2013; p 91

3 Brenner, 2003 
crítico. Estos se producirían no solo en cada uno de los cambios de ciclo de los que nos habla Arrighi ${ }^{4}$, sino fundamentalmente en el punto de cambio de los sistemas de producción y acumulación como sostiene Lefebvre ${ }^{5}$.

Así, en este punto crítico, superpuestas las líneas de los ciclos de producción-acumulación y de los sistemas de producción, el neoliberalismo, a través de la expansión de la industrialización y la urbanización, conseguiría supeditar el espacio social al continuo producir de rentas del capital y a la permanente acumulación de plusvalías.

El desarrollo de una solución por infraestructuras ${ }^{6}$ supone introducir el espacio como variable del sistema de producción y acumulación capitalista, y por tanto, factor de las relaciones sociales de producción. Así, este modelo daría forma espacial al desmantelamiento del bienestar y completaría el trasvase de las rentas del trabajo a las rentas del capital. Sin duda, este es un signo de la forma espacial adoptada en el re-escalamiento neoliberal ${ }^{7}$ 9 , de tal manera que la ciudad adoptaría un papel de producción de capital y de dominación sobre el espacio social. Esto vendría a suponer una intervención de la urbanización sobre las relaciones sociales de producción, transformando las formas de vida asociándolas al ocio, al consumo y al divertimento. Así es como las relaciones entre los individuos quedarían marcadas por la posición social, adquirida por su capacidad de acceso a bienes y servicios. Con ello, el espacio quedaría abocado a su condición de mercancía y para cumplir la misión de otorgar valor simbólico a la posición social, del mismo modo que en otros momentos lo cumpliera la vestimenta o la adquisición de determinados productos. Esta consideración ideológica del espacio no es una novedad, pero el neoliberalismo ha tenido la capacidad de concebir un espacio alejado de las relaciones de clase, abstracto, producido por la dependencia del individuo con el consumo y la mercancía.

Convertido en mercancía, el espacio se somete a los rigores de la competencia, devenida en la fase neoliberal por la necesidad de las organizaciones capitalistas por adquirir ventajas competitivas por su localización ${ }^{10}$, bien por el equilibrado nivel tecnológico de sus estructuras, bien por su incapacidad por conseguirlo. Esto conduce a recuperar espacios urbanos bajo una lógica competitiva, mejorando entornos para atraer la localización de usos y empresas, a través de inversiones de capital.

\section{Objetivos metodológicos y campos de análisis}

Nos aventuramos, por tanto, a verificar si bajo este modelo de producción de espacio, han basculado los parámetros sociales hacia la producción de capital, quedando los instrumentos de reproducción bajo dominio neoliberal, ya sea a través

4 Arrighi, 2007

5 Lefebvre, 1969; p 92

6 Harvey, 2013

7 Brenner, 2003

8 Brenner, 2013

9 Brenner, Peck \& Theodore, 2009

10 Harvey, 1982 
de privatizaciones, de precios inmobiliarios o, como pretendemos comprobar, del uso del espacio. Todos estos factores son distintivos del proceso de reorganización neoliberal, pero el uso del espacio sugiere la destrucción de las estructuras físicas y sociales pre-existentes, o en su defecto a relegarlas a una posición periférica dentro del sistema de producción o incluso apropiándoselas como rasgos folclóricos de una transformación llevada a cabo bajo una lógica de destrucción creativa.

Por otro lado, el periodo objeto de estudio coincide con el de mayor expansión de la ciudad en términos financieroinmobiliarios ${ }^{11}$, en función de un modelo urbano que parecía condicionar la reproducción social ${ }^{12}$ y que prescindió de elementos de regulación de la planificación urbana ${ }^{13}$ como instrumento de equilibrio territorial y social. Con estos objetivos, vamos a recurrir a la comparación espacial de parámetros que aportan referencias de las relaciones sociales de producción dadas en Madrid. Así, se ha recurrido a una comparativa mediante series anuales, cuyos valores se han obtenido de diferentes instituciones, según las anualidades y grado de desagregación disponibles - en nuestro caso, la sección censal-. Esto dificulta en cierto sentido su comparación, puesto que la heterogeneidad de fuentes da como resultado referencias anuales diversas y, por tanto, la comparación no puede hacerse de manera anual. Sin embargo, al tratarse de un análisis histórico, nos interesa considerar los efectos sobre el período completo, más que por cada año del mismo.

La consideración de parámetros se ha realizado con el objetivo de obtener suficientes datos que confirmen si la expansión neoliberal de la urbanización ha influenciado la preponderancia del espacio económico sobre el social. Así, la actividad económica nos puede dar una muestra de la resistencia de cada espacio estadístico para transformar las estructuras morfológicas de los distintos ámbitos; también refleja la competencia que se da entre lugares por aprovechar las transformaciones formales en beneficio de la expansión de un tipo de actividad concreta. Esta competencia espacial se apoyaría en la competencia de usos y por tanto, darían una muestra de la mercantilización del espacio - físico y social-, al condicionar las formas de vida existentes a las formas económicas dominantes.

En este sentido, la competencia por transformar la estructura formal de la centralidad nos la podría facilitar dos parámetros. De un lado, la inversión pública llevada a cabo en la transformación de la imagen y la estructura urbana. De otro lado, el Producto Interior Bruto y los precios inmobiliarios nos dan una idea del tipo y la escala del capital gestionado en el área central de la ciudad de Madrid. Lamentablemente, estas series sólo están disponibles por unidades censales a partir del año 2004, por lo que su referencia temporal debe ser tenida en cuenta relativamente próxima al punto final de nuestro trabajo. Sin embargo, nos parece que la comparación con otros parámetros permite considerarlo como un dato útil para evaluar la producción y reproducción de capital en la centralidad de Madrid.

11 Fernáncez, 2006

12 Roch, 2008

13 de Santiago Rodríguez, 2012 
Por tanto, la consideración de las series anuales consideradas, nos dan la referencia escalar y morfológica que requiere nuestro estudio, y su localización nos aporta información para evaluar la práctica espacial llevada a cabo durante la expansión neoliberal. La conjunción de estos datos nos aporta una visión sobre el espacio vivido asociado a la morfología resultante y la percepción espacial de la centralidad dentro de un contexto de hegemonía de los valores neoliberales y su discurso de ascenso social y excelencia.

\section{Apuntes sobre de la expansión neoliberal en Madrid}

Aunque no vamos a entrar en consideraciones de carácter histórico, no debemos obviar que el periodo estudiado se ha definido por un modelo de planificación urbanística que facilitó la expansión urbana hasta el límite de la capacidad del suelo disponible. Para que fuera posible, se sucedieron cambios políticos, sociales, económicos y normativos que permitieron que la ciudad de Madrid traspasara la conceptualización de la austeridad ${ }^{14}$ del Plan General de 1985 hasta la definición del expansionismo ${ }^{15}$ en el planeamiento vigente.

Puesta la atención en las repercusiones de este modelo expansivo en la periferia, las repercusiones sobre el centro urbano han sido analizadas con menor intensidad. Atraídos por la menor regulación urbanística, por la facilidad para extraer plusvalías de las inversiones y por un cierto deslumbramiento académicointelectual ${ }^{16}{ }^{17}$, inversores privados y públicos llevaron a cabo una intensa transformación de la periferia, dejando el centro urbano como un espacio decorativo, atractor de turismo y localizador de actividades secundarias ${ }^{18}$. Sin embargo, no debemos caer en la tentación de considerar los centros urbanos como lugares residuales de la expansión neoliberal, y por ello pretendemos comprobar si no ha sido uno de los grandes objetivos de esta expansión o, al menos, el producto acabado de una competencia espacial encaminada a obtener plusvalías dentro de la redefinición del sistema de producción.

El análisis del periodo que comienza con la aprobación del vigente Plan General $^{19}$ y finaliza con el estallido de la crisis actual en torno al año 2008, nos permite

14 Campos Venuti, 1981

15 de Santiago Rodríguez, 2012

16 Aunque durante este periodo se da una gran cantidad de textos acerca de las periferias, nos parecen especialmente significativos, por su influencia en diversos ámbitos, los textos al respecto del arquitecto Rem Koolhas, quien quedó deslumbrado por la falta de referencias históricas y culturales de las periferias de las ciudades.

17 Koolhass, 2006

18 Ynzenga, 2005

19 El Plan General de Ordenación Urbana de 1997 se aprueba con la idea de los planificadores de disponer de la mayor cantidad posible de suelo para su desarrollo, lo que en la práctica supuso poner a disposición de nuevos desarrollos urbanísticos la totalidad del suelo del municipio de Madrid. Se perseguía la idea de intervenir sobre los precios finales de la vivienda, al incrementar la oferta de suelo, lo que acompasaría la oferta y demanda de suelo y por tanto de vivienda. El resultado fue una liberalización del suelo y de las relaciones de producción de espacio, sin que por ello se consiguiera una reducción de los precios del producto resultante. Al contrario, el mercado inmobiliario se benefició de un sistema que le permitió una gran expansión inmobiliaria con las 
analizar lo ocurrido durante un ciclo de máxima expansión neoliberal. Esta se ha caracterizado por la sobreproducción del espacio, con la pretendida intención de garantizar la adquisición de vivienda a amplios y diversos sectores sociales, lo que ha llevado a desarrollar en la periferia grandes polígonos de viviendas, infraestructuras viarias, hídricas y eléctricas; mientras, se invertía en la transformación de la estructura y la imagen de la centralidad. Ambas dinámicas parecen dar forma a una solución espacial que, a nuestro modo de ver, ha sustentado la ilusión del ascenso social a amplios sectores de la sociedad urbana.

Esta operación de asimilación de los valores de prestigio social supone considerar en el espacio como el lugar de representación de la posición social del individuo, algo que quedaría sustancialmente ligado con la práctica espacial ${ }^{20}$ a través de la cual los individuos perciben su espacio social conjugando su realidad cotidiana, esta es en la que se dan la relaciones sociales de la producción, y su realidad urbana, esta es su entorno vivencial, donde se concretan los usos y formas sociales.

En este sentido, el mercado inmobiliario asocia las relaciones sociales de la producción con las formas urbanas, de tal manera que estas determinarían la morfología social, y con ello limitarían la capacidad de apropiación del espacio. Por consiguiente, esta producción segregada del espacio se ha venido apoyando en un discurso de ascenso social con el cual se ha garantizado un esquema de dominación a partir de la capacidad de apropiación del espacio. En consecuencia, el lugar y la morfología existentes son susceptibles de ser transformadas por el sistema de precios asociados. Así, los rangos de precios de la vivienda ${ }^{21}$ sustraerían al individuo de su capacidad para apropiarse del espacio, impidiéndole llevar adelante su capacidad creativa. Limitada esta, la destrucción de las estructuras formales y morfológicas que han determinado históricamente el espacio, permitiría a las clases dominantes ejercer su dominación sobre el espacio, disponiendo del espacio central para llevar adelante la producción de su propio espacio.

Para dar cuenta a este esquema de producción espacial, las inversiones públicas sobre el espacio central de la ciudad, revelan su capacidad para transformar las formas urbanas, y estas transforman los usos y la actividad económica en alguna de las direcciones vistas anteriormente.

Como iremos viendo, la dimensión espacial de la acumulación de cada parámetro objeto de análisis da como resultado unas formas en mosaico consecuencia del reforzamiento de un espacio diferenciado, segregado e indicativo de la posición de los individuos en la escala social. Esta formas de acumulación podrían ser fruto, a su vez, de una competencia espacial, rasgo característico del neoliberalismo y que vendría a poner de manifiesto que Madrid habría entrado en una fase en donde el sistema financiero estaría buscando el lugar más apropiado para fijar los excedentes obtenidos en la producción de la periferia, así como transformando el espacio para

posteriores consecuencias que desembocaron en la crisis del sistema financiero e inmobiliario de 2007.

20 Lefebvre, 2013; p. 91

21 Fernández; Roch, 2012 
dotar a las organizaciones allí instaladas de ventajas competitivas respecto de otras. De esta manera, cada unidad del mosaico tendería a la especialización para atraer inversiones con las que reproducir capital, facilitaría la exclusividad ${ }^{22}$, para hacer destacar unos productos sobre otros, y con ello atraer al consumo.

Con ello, se conseguiría que el lugar, producido a partir de la apropiación del espacio por las clases dominantes, represente la posición de los individuos dentro del discurso de excelencia y prestigio, verificando con ello el proceso de dominación de una clase social sobre otra.

\section{Expansión financiera, desmantelamiento del bienestar y transforma- ción de los modos de vida}

La competencia de cada unidad del mosaico serviría, pues, para introducir al espacio dentro del sistema de producción convirtiéndolo en mercancía, pero también para alcanzar una posición en el sistema urbano, asentado sobre la construcción de la ciudad global. Considerada esta ${ }^{23}$ como un nodo de acumulación de formas post-fordista de producción y como un nodo de gobernanza regional y local del Estado, la contradicción entre ambos aspectos ha llevado a la preponderancia de las fuerzas de producción sobre la reproducción social.

Así, las tareas de acumulación y gestión del capital producido se han antepuesto a las asociadas al espacio social, entre las que debemos considerar las formas de vida, donde el consumo se convierte en parámetro fundamental de sociabilización. Esto daría explicación a las formas de acumulación del tipo de actividades en el espacio central de Madrid, determinando una organización espacial acorde a la necesidad de incrementar la ilusión del consumo y la imagen como referencia de ascenso social de los individuos.

Por otro lado, la preponderancia de las formas de producción ha puesto de manifiesto la necesidad de una expansión planetaria con la que llevar a cabo la construcción de un mundo a imagen y semejanza de las capas dirigentes, es decir, donde imperen sus formas de vida ${ }^{24}$. En el caso de Madrid, paradójicamente, la construcción de este mundo solo ha sido posible hacerlo a partir de la renuncia de la burguesía a un espacio propio, apropiándose, en cambio, de espacios históricos de la aristocracia pasada, representando un espacio donde se subordinan las relaciones sociales a la mercantilización ${ }^{26}$, al intercambio comercial, destruyendo para ello aquellas formas previas que contenían una referencia espacial vinculada a la morfología social heterogénea que la sustentaba.

22 Harvey, 2007; p 420

23 Brenner, 2003

24 Esta idea es ampliamente desarrollada por Arrighi en varios de sus textos, en donde recurre a Marx y Engels para determinar que la principal aspiración de la burguesía es la de imponer los modos de producción capitalistas en todo el planeta y que ello lleva consigo, irremediablemente, el dominio de las formas de vida de la burguesía.

25 Marx; Engels, 2012

26 Lefebvre, 2013; p 100 
Siendo la mercantilización la principal prioridad de una clase que requiere del espacio tan solo para la producción y el intercambio de mercancías ${ }^{27}$, debemos preguntarnos si en este proceso hay algún aspecto que condiciona la localización espacial de cada clase. Siguiendo los planteamientos de Arrighi ${ }^{28}{ }^{29}$, la expansión neoliberal ha supuesto un largo proceso de re-escalamiento no solo del Estado, sino incluso de las organizaciones capitalistas, que supone, de hecho un cambio dentro de las distintas fases de producción y acumulación. Coincide, pues, con la transición de una fase de producción material a otra de expansión financiera, lo que ha hecho cambiar las referencias conceptuales del trabajo y de clase $y$, a nuestro juicio, también las espaciales. La gran sobreproducción espacial de la periferia que hemos observado en el caso de Madrid ${ }^{30}$ habría ido encaminada a alojar a las capas medias urbanas fuera de la centralidad ${ }^{31}$, al tiempo que se llevaba a cabo la depuración de la estructura morfológica del centro urbano.

En este contexto, la expansión planetaria neoliberal habría supuesto la pérdida de la capacidad de la reproducción social para llevarse a cabo fuera de la economía de mercado, lo que incrementaría la competencia entre organizaciones capitalistas ${ }^{32}$ - expresado fundamentalmente en una reducción de costes mediante la especialización y las innovaciones ${ }^{33}$-, pero también sometiendo a los individuos a la disciplina de los organizadores de la producción, esto es, haciéndoles adoptar sus formas de vida, tal y como aventuraban Marx y Engels.

Esto nos lleva a pensar que la estructura económica estaría produciendo un cambio en los cuadros de representación social, apoyada en el papel de la urbanización para absorber los excedentes de capital y de trabajo, y en su capacidad de dominación sobre las capas populares, imponiéndoles formas de vida ajenas a ellas ${ }^{34}$. De esta manera, entendemos que se ha producido un cambio tal que parecen disolverse los vínculos históricos existentes en la sociedad capitalista, produciendo unos nuevos en un largo proceso de transformación, que aunque se apunta su finalización, no parece haber sido superada aún - de hecho, si llevamos los planteamientos de Brenner hasta el final, esta transformación no llegaría nunca, pues esa es una ca-

27 No es el objeto de este artículo, pero incluso en las inversiones más recientes, el caso de Madrid es paradigmático. A lo largo del tiempo, incluso en las dos últimas décadas, la burguesía madrileña ha tendido a reproducir el espacio de clases hegemónicas anteriores a ella, destruyendo y volviendo a construir espacios de los sectores populares, en lo que podríamos llamar una destrucción creativa que garantizara la reproducción de capital.

28 Arrighi 2007

29 Arrighi, 2014

30 Observatorio Metropolitano, 2011

31 Debemos hacer notar, aunque sea de manera parcial, que en este caso no solo se ha tratado de un desplazamiento geográfico de las clases sociales, sino también de un desplazamiento político. El traslado de las capas medias desde el centro urbano hacia las periferias urbana y metropolitana de Madrid, también se ha reflejado en el desplazamiento de la centralidad del sistema, despojándolas de su capacidad de gestión del mismo, y asimilándolas a capas servidoras, gracias a una estructura laboral progresivamente precarizada.

32 Brenner, Peck \& Theodore, 2009

33 Harvey, 1982

34 Harvey, 2007; pp 106 
racterística del neoliberalismo, una continua transformación para adaptarse a las condiciones que le permitan la máxima obtención de beneficios.

La ilusión del ascenso social tiende a agudizar la contradicción entre capital y trabajo, es decir, los beneficios capitalistas se sitúan por encima de las rentas del trabajo, por la vía de sacrificar no solo los salarios de gran parte de la clase trabajadora, sino también todas aquellas instituciones y mediaciones que otrora garantizaran el equilibrio y la cohesión social. El neoliberalismo habría conseguido trasladar a los individuos la percepción de compartir los logros de este modelo social, cuando en realidad se estarían sentando las bases de un modelo coercitivo por la pérdida de las condiciones de equilibrio. De esta manera, el desmoronamiento de todo el modo de producción basado en el equilibrio entre producción y renta ${ }^{35}$, origina el fin de la cohesión planteada desde la época del fordismo como base esencial del proceso de acumulación capitalista ${ }^{36}$ y que tenía como condicionantes los salarios crecientes, el pleno empleo, los servicios, la planificación urbana, las prestaciones sociales o las pensiones públicas, es decir toda una serie de mediaciones que atenuaban el conflicto social y permitían, al menos en teoría, un crecimiento ilimitado de la producción y de la ganancia capitalista. El neoliberalismo no solo intensifica esta destrucción referencial de las clases sociales, sino que supone una redefinición de la escala de los mismos, obligando con ello a un reescalamiento del Estado y, por tanto, de cada una de las estructuras que lo componen. Lejos de significar el final del Estado y de su poder, el neoliberalismo parece abocar a una nueva definición de su capacidad coercitiva, a partir de la supeditación del espacio social al económico, y la preponderancia de la estructura de acumulación sobre la reproducción social. En un ejemplo de estas ideas, las operaciones llevadas a cabo en el centro de Madrid, reflejan esa preponderancia sobre el espacio social donde las inversiones públicas han facilitado cambios morfológicos con la implantación de usos donde se consolida una imagen global y se representan valores dominantes, tal y como veremos más adelante [ver Figura 4].

En este sentido, no debemos entender que este cambio se produce de manera puntual, sino que es un largo proceso que se inicia años atrás ${ }^{37}$, seguramente a partir de la crisis de acumulación vivida en los años 1990, pero que es a partir de la expansión financiera neoliberal cuando se agudiza el desmantelamiento de lo urbano, se intensifica la producción de un espacio segregado por capacidad de renta y endeudamiento, y se acentúa la elitización de los espacios centrales.

De esta manera, el espacio podría pasar a ser entendido como un instrumento de coerción y dominación, en el que la burguesía, como clase dominante, y los sec-

35 Según los modelos inmobiliarios determinados por Fernando Roch, este equilibrio entre renta y producción se habría llevado a cabo bajo un modelo de acceso limitado a la propiedad, pero sería ampliamente superado por un modelo de propiedad universal, donde los valores de renta no dependen de la producción urbana, sino que se confía al sistema financiero la capacidad de acceso a la propiedad, y por consiguiente, al instrumento regulador, o intermediario entre renta de los individuos y sistema de producción.

36 Aglietta, 2001

37 Varoufakis, 2013. 
tores asalariados avanzados -fundamentalmente trabajadores intelectuales y técnicos, según se desprende de los trabajos de Lacalle ${ }^{38}$ para el caso de España- irían ocupando el espacio de prestigio histórico con la finalidad de elitizarlo y así producir una especie de mercancía espacial que pueda ser consumida por el resto de clases. En esta operación de apropiación simbólica, o de representación de espacio, se requieren fuertes inversiones, fundamentalmente de carácter público, por lo que las plusvalías colectivas habrían servido para reproducir capital y elitizar lugares populares o tradicionales ${ }^{39}{ }^{40}$, con la idea de recuperar las inversiones que el urbanismo reformista forzó en los años de 1970-1980 para equilibrar socialmente las ciudades.

Nos veríamos entonces obligados a tener en cuenta que el desmantelamiento del bienestar habría afectado al ámbito urbano incluidos sus aspectos cultural y simbólico, de tal manera que nos encontraríamos inmersos en un proceso de pérdida de la ciudad como espacio de reproducción social a favor de la reproducción del capital. Esto nos llevaría a valorar si la transformación que ha llevado a cabo la expansión neoliberal tiene su reflejo en el espacio urbano y si éste adopta unas formas que faciliten la reproducción de capital, o si, por el contrario, estas formas permiten la aparición de expresiones de resistencia a la expansión neoliberal.

En el estudio que hemos llevado a cabo sobre la acumulación de capital económico, social y simbólico que dan lugar a las transformaciones vividas en el centro de Madrid en las dos últimas décadas, podemos intuir que se ha incrementado la segregación espacial y se ha intensificado el espacio diferenciado - amoldando los usos a los requerimientos neoliberales de mercantilización de la vida-. Sin embargo, también es posible pensar que las formas resultantes de las diferentes estructuras de acumulación, fragmentadas a modo de mosaico, dejan entrever una resistencia al modelo urbano, quizá una moderna manifestación del conflicto social y de clase.

\section{Estructuras de acumulación de capital en Madrid}

Ya hemos visto cómo el neoliberalismo ha intensificado su expansión planetaria incorporando a cientos de millones de personas en un ciclo de consumo que ha hecho transformar la percepción de clase y cuyas vinculaciones con el espacio urbano parecen razonables a tenor de las consideraciones sobre el modelo inmobiliario planteado por Roch, donde se vincula la producción del espacio con la transformación morfológica a modo de nueva esquema de dominación a partir de la acumulación de capital a partir de la apropiación de las rentas del trabajo.

Las consecuencias sobre el espacio social han sido muy evidentes en la periferia de Madrid, donde esta acumulación por desposesión se ha llevado a cabo a partir de la adquisición de viviendas, exigiendo a las capas populares un esfuerzo por alcanzar el estatus social anhelado muy superior al exigido para otras capas y clases sociales. Esto ha dado lugar a un incremento significativo del número de desahucios

38 Lacalle 2006

39 Esto daría a las inversiones un marcado carácter ideológico, por cuanto sustentarían una transformación morfológica del espacio que las soporta.

40 Morcillo, 2017 
motivado por la incapacidad de las capas populares por mantener su estatus con las rentas del trabajo, una vez desenmascarada la ilusión creada por el sistema financiero.

Una vez delimitada la apropiación de rentas a través de diversas fórmulas, se ha intensificado de la competencia, no solo entre las organizaciones capitalistas en pugna por los beneficios, la tecnología y el conocimiento ${ }^{41}$, sino también entre los individuos, que aspiran a una mejor posición en la escala social. Trasladándolo al ámbito urbano, podríamos hablar de una adaptación de la estructura económica y la oferta de las ciudades para atraer capital en forma de inversiones, negocios, ocio o turismo ${ }^{42}$. Este nivel de competencia espacial subyace en el análisis de indicadores que se han ido sucediendo en las dos últimas décadas y que se materializa en los ranking de ciudades que elaboran diferentes analistas e incluso instituciones públicas como el Ayuntamiento de Madrid $^{43}{ }^{44}$, con la idea de atraer inversiones, capital y rentas con las que posicionarse en la «escala urbana neoliberal».

Estas clasificaciones han producido un discurso en el que se ha apoyado el redimensionamiento de la ciudad global ${ }^{45}{ }^{46}$, de tal manera que las ciudades adoptarían una nueva posición en las formas de organización del capital y por tanto definiendo su posición dentro de una escala global de ciudades. A este respecto, en numerosos documentos urbanísticos y económicos de Madrid, se apunta la necesidad de mejorar la posición de Madrid en estas clasificaciones, para lo cual se sugieren medidas o inversiones para hacer escalar a Madrid en la clasificación.

Por consiguiente, la idea de competencia espacial está presente tras la solución espacial infraestructural que ha motivado gran parte de las inversiones de capital colectivo en los espacios centrales de Madrid. Sin embargo, estas inversiones han dependido mucho de factores simbólicos, es decir, no solo se buscaba el máximo plusvalor en la inversión, sino que se han localizado en aquellos ámbitos en los que se consiguiera una mayor reproducción, lo que ha llevado a acumular capital en forma de infraestructuras, equipamientos y usos en su búsqueda de las condiciones óptimas de reproducción de capital.

Para el caso de Madrid, recurrimos a los mapas de la acumulación del PIB como una muestra del tipo y escala del capital gestionado en cada unidad de análisis. La geografía resultante nos deja un mosaico que da pie a considerarlo como la intensificación de la competencia espacial ya que, puesto en relación con el sistema de precios inmobiliarios, nos aporta una idea de la estructura morfológica y del espacio vivido resultante de esta competencia.

Sin duda alguna, los niveles de competencia parecen demostrarse en la transformación de las relaciones centroperiferia, que resultaría una manera de interpre-

$41 \quad$ Harvey, 1982

42 Harvey, 2007

43 Oyarzábal de Miguel, 2012

44 Ramos, 2013

45 Smith, 2005

46 Brenner, 2003 
tar la producción de la ciudad global. A una periferia que aloja las espacios de la reproducción social se le impondría un espacio central, nodo para la gestión del sistema de acumulación, que condicionaría, a su vez, las formas sociales de relación en la periferia. Así es como las formas de acumulación de las actividades económicas nos muestran una vez más un espacio muy fragmentado, y donde se atisba la estructura de un espacio diferenciado, morfológicamente determinado por los precios inmobiliarios. Esto supone, de alguna manera, la producción de un espacio abstracto $^{47}$ donde el espacio social quedaría supeditado al económico, esto es, las relaciones de producción dificultarían a los individuos la percepción espacial y por tanto la apropiación del mismo.

En función de la ya expuesto, vamos a iniciar nuestro análisis empleando el parámetro de Producto Interior Bruto (PIB) [ver Figura 1], obtenido de la estadística municipal, y lo referenciaremos con los precios inmobiliarios obtenidos fundamentalmente a través de buscadores inmobiliarios. Este parámetro estadístico nos da una idea de la producción de capital llevado a cabo, vinculado a la actividad económica que tiene su centro ocupacional en el lugar referenciado. Aunque no clarifica los niveles de renta de la población residente, sí nos aporta información sobre el capital que se produce en el espacio asociado, y por tanto, guarda algún tipo de relación con el uso de los centros urbanos y las actividades allí dadas. Recientemente, el Ayuntamiento de Madrid ha publicado una serie de mapas de renta correspondientes al año 2016, y aunque no se encuentra dentro de nuestros años de estudio, sí nos facilita una referencia válida para corroborar algunos aspectos derivados del análisis de la acumulación de PIB. Esto nos resulta especialmente interesante pues no solo nos otorga información sobre la cantidad de capital producido, sino también sobre la estructura económica existente y el grado de especialización y diferenciación espacial. En este sentido, acudimos a tomar valores relativos medidos en función del valor medio de cada serie, y así poder conocer la posición de cada unidad espacial en relación con la media; medido a lo largo de series anuales, nos va a permitir deducir el esfuerzo realizado por cada unidad por alcanzar su nivel de producción de capital en la estructura económica resultante.

Aunque es una variable con muchas aristas, consideraremos los precios inmobiliarios como capital fijo, concretamente como renta fija, y como forma de reproducción de capital. Esto es especialmente interesante para el análisis del centro, pues tienen un carácter morfológico y de representación social que nos resulta muy útil en el análisis que estamos llevando a cabo y nos permite vincular la competencia espacial con la percepción que del espacio hace cada clase social. Esto es porque tras de sí se esconden las relaciones sociales que determinan las relaciones espaciales y de producción de la ciudad y por tanto, condicionan de alguna manera la reproducción de capital económico que nosotros hemos referenciado en los valores del PIB.

La incorporación a nuestro análisis de los precios inmobiliarios nos debería permitir verificar si se está llevando a cabo una diferenciación espacial en el centro

47 Lefebvre, 2013 
urbano, así como comprobar si el esfuerzo por alcanzar el estatus es diferente en función de la posición de clase, tal y como nos indican los trabajos de Fernández y Roch $^{48}$. Corresponde este estudio a la intención de los autores por encontrar las pautas de la evolución inmobiliaria en los años precedentes a la crisis económica de 2008, es decir, aquellos de mayor expansión de la urbanización en Madrid.

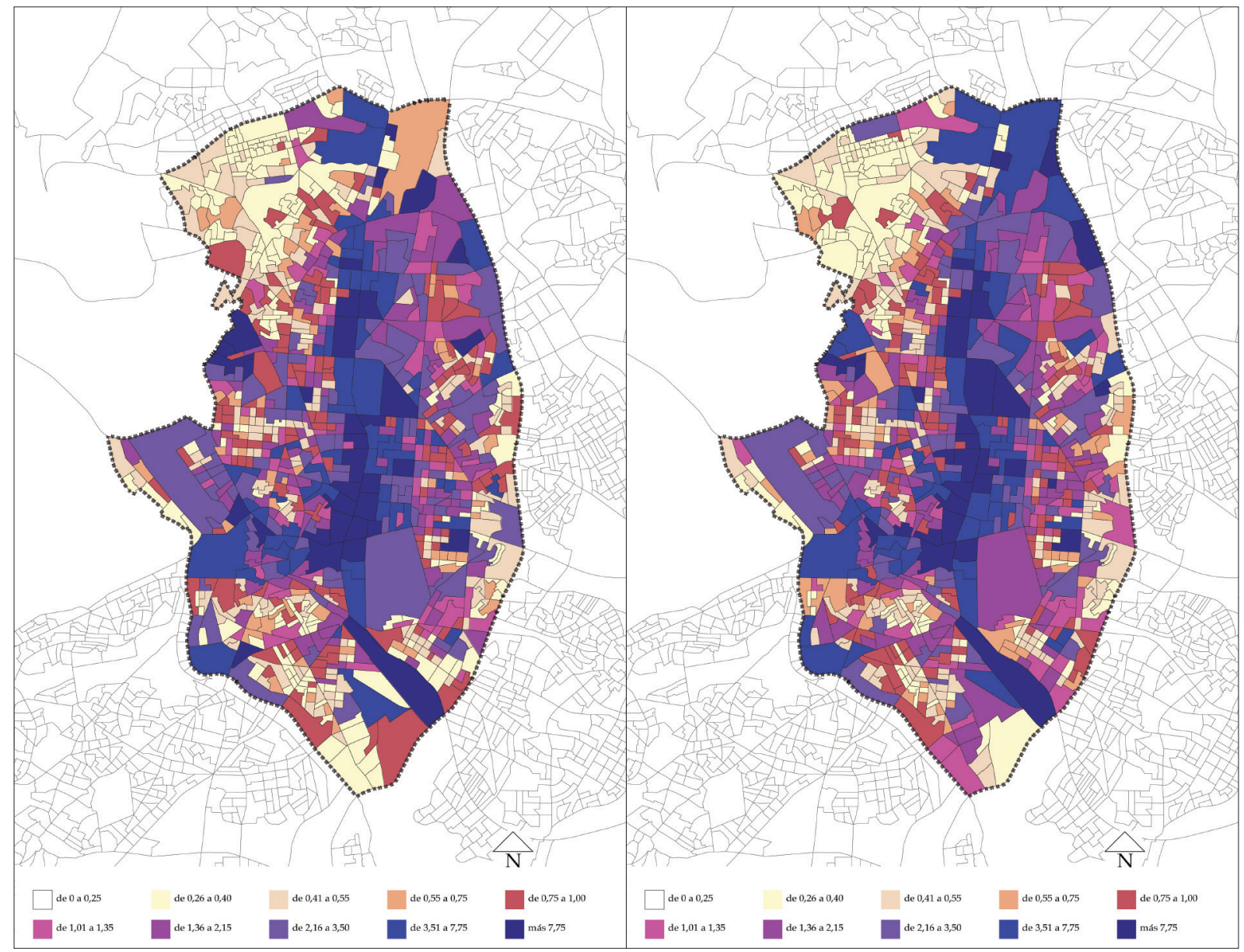

Figura 1. Evolución de los valores relativos de PIB medidos en relación al valor medio de los mismos en cada año. Años 2004 (izq.) y 2008 (dcha.).

Fuente: Elaboración propia a partir de los datos del Instituto de Estadística de la Comunidad de Madrid.

Por otro lado, según se desprende de los trabajos de de Santiago ${ }^{49}$, este período no puede ser entendido en términos urbanísticos sin considerar la evolución del planeamiento y los cambios políticos y económicos dados en los años 1990, en los que ya estaba en marcha el reescalamiento del Estado. Desde nuestro punto de vista, el mercado inmobiliario se fue fraguando en esos años en los que el neoliberalismo iba apuntando su configuración espacial y por tanto, debemos remitirnos a períodos más amplios para evaluar las consecuencias que sobre el espacio social han tenido las prácticas inmobiliarias dadas en Madrid. Así, guiándonos de datos elaborados a partir de anuncios inmobiliarios y del trabajo realizado por Fernández y Roch, podemos entender que el esfuerzo por adquirir una vivienda no se ha realizado por

48 Fernández; Roch, 2012

49 de Santiago, 2012 
igual en la ciudad de Madrid, y que corresponde a los ámbitos donde se localizan los sectores de menores rentas donde mayor esfuerzo se ha realizado por alcanzar una posición social, determinada esta por la adquisición de vivienda. Esta podría ser la traducción espacial de la competencia social dada entre individuos que ha venido a llevar a cabo el neoliberalismo bajo el discurso de la excelencia y la posición social.

En el caso del centro de Madrid, el estudio anteriormente citado nos pone en alerta acerca de la heterogeneidad del mapa de rentas, lo que de alguna manera viene a coincidir con la geografía resultante de la producción de capital. Paulatinamente, a lo largo de los últimos treinta años, las rentas inmobiliarias [ver Figura 2] en el centro se han ido acumulando en torno al eje nortesur, muy homogéneo en este aspecto, mientras el resto del área central muestra señales de fragmentación, resultado, seguramente, del esfuerzo desigual por alcanzar la posición y el estatus anhelado por cada grupo social.

Al poner en relación las geografías de acumulación de capital producido con las rentas inmobiliarias, observamos que el eje Norte-Sur va reforzándose a lo largo del tiempo, consiguiendo un espacio de gran homogeneidad que contrasta con la heterogeneidad y fragmentación del resto de la Almendra Central. Este mosaico podría ser la consecuencia descrita por Harvey ${ }^{50}$ respecto de la diferenciación espacial en busca de la mejora competitiva respecto de otros espacios. La heterogeneidad que se aprecia en el mosaico no debe por tanto entenderse como la capacidad del mercado inmobiliario por sostener una morfología social diferenciada, sino al contrario, como la necesidad de depurar esta estructura incrementando la competencia entre espacios en búsqueda de una diferenciación que atraiga sectores social con mayor capacidad de renta, pero también sectores sociales con valores culturales y usos urbanos asimilados.

Es muy posible que esta situación competitiva haya atraído a un sector de las capas medias, con mayor nivel de formación pero con una menor capacidad de rentas, hacia ámbitos centrales donde se requiere mayor nivel de transformación de la forma urbana. Estos ámbitos, serían asimilados a través de la actividad económica, dando lugar a un proceso que algunos autores denominan como gentrificación y que bajo nuestro punto de vista, no dejan de ser una forma de distinción y exclusivización resultado de la intensificación de la competencia espacial y entre individuos.

La comparativa de las geografías de acumulación de rentas nos deja la impresión de una cierta expansión hacia los límites de la Almendra Central que nos sugiere una dependencia mutua de ambas geografías; de hecho, ambas parecen tener la capacidad de producir espacios de segregación que consolidan la exclusividad de unos y relegan a otros a un estado periférico tanto en la generación de flujos de actividad económica como en la producción de un espacio que dé servicio a la centralidad. En realidad, esta situación corresponde a una repercusión espacial de la estrategia neoliberal que permite el auge de un espacio solo a partir del declive de otro, algo que es posible encontrar en los planteamientos sobre la formación espa-

50 Harvey, 2007 
cial de los modelos capitalistas deArrighi ${ }^{51}$, pero también en Brenner ${ }^{52}$ en el análisis del re-escalamiento del Estado, que impone una reestructuración urbana entrando en competencia unos lugares frente a otros.

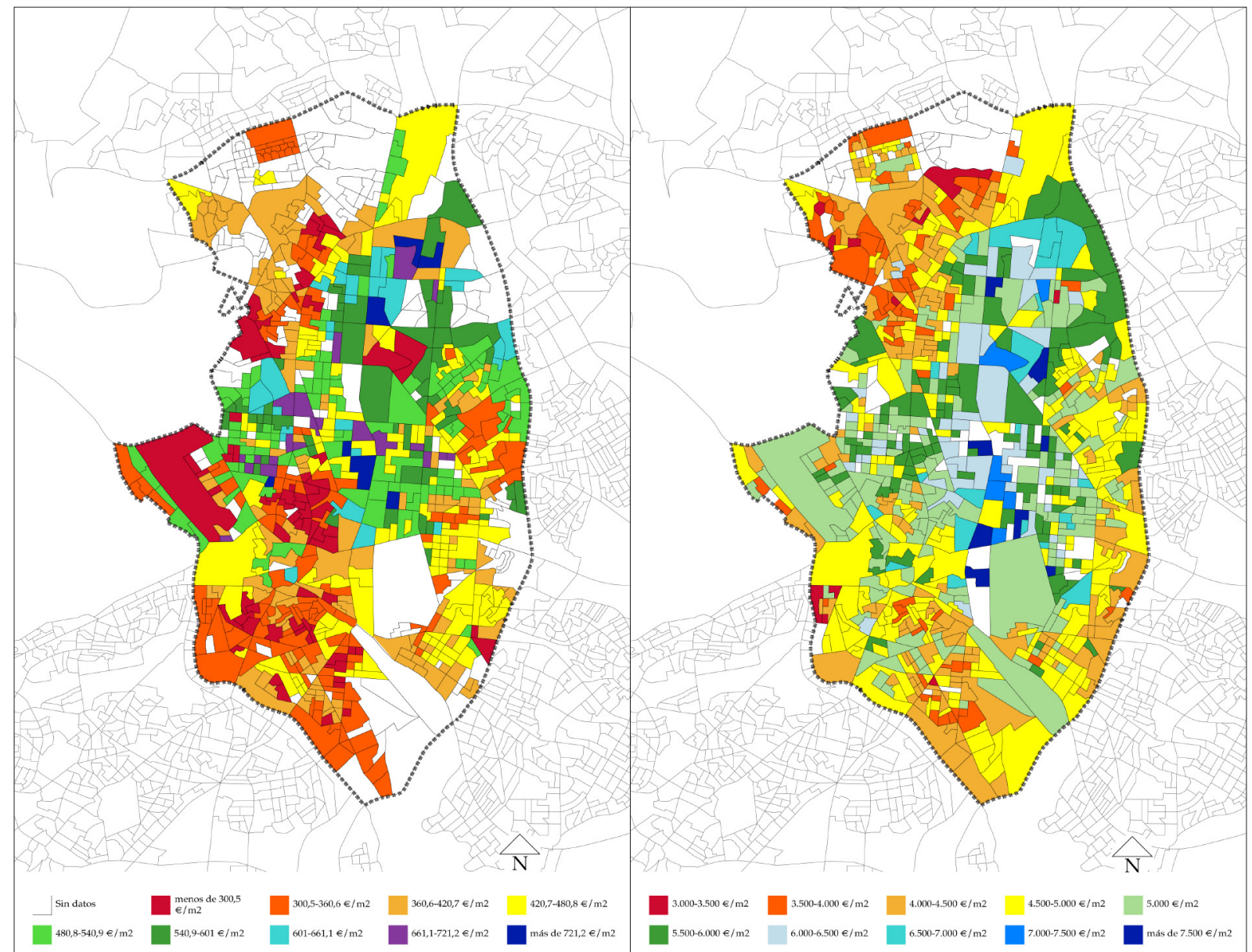

Figura 2. Precios inmobiliarios unitarios en el año 1986 (izq.) y precios inmobiliarios unitarios en el año 2006 (dcha.)

Fuente: Elaboración propia a partir de datos de Fernando Roch Peña.

Esta relación entre capital producido y capital fijo es la base de todo sistema de acumulación capitalista, que en el caso del sector inmobiliario ha dado lugar a una importante producción teórica con el objeto de conocer los mecanismos de producción de capital. A nuestro modo de ver, estos métodos de análisis tienden a ignorar, sin embargo, la capacidad de producción del espacio que ha tenido lugar a lo largo de la fase de expansión financiera que estamos analizando. En el caso de Madrid el modelo inmobiliario apuntado por Roch ${ }^{53}$ relaciona de una manera inequívoca espacio y capital, pero también nos anuncia una estructura de clases en donde se

51 Arrighi, 2014

52 Brenner, 2003

53 Roch, 2008; Roch, 2015. Los mapas de la Figura 2 son el resultado de una serie de investigaciones dirigidas por Fernando Roch y en las que ha participado el autor del presente artículo para el año 1986. Los datos han sido obtenidos a partir de los anuncios aparecidos en prensa y en los portales inmobiliarios de internet. En el caso del mapa correspondiente al año 1986, los datos iniciales estaban reflejados en la moneda circulante, es decir, la peseta, por lo que con posterioridad se han convertido a euros para poder realizar las adecuadas comparaciones anuales. 
incrementan las diferencias sociales a través del espacio y donde el factor trabajo queda vinculado con más intensidad a los sectores populares y desfavorecidos ${ }^{54}$. El papel que juega en este modelo la centralidad nos parece importante, al ser el espacio simbólico que demostraría la posición social, el lugar donde se materializaría el consenso social a través del uso del espacio, fundamentalmente a través de la incorporación generalizada al consumo y al ocio de todos los sectores sociales. Sin duda alguna los planteamientos de Garnier ${ }^{55}$ respecto de la dominación de las clases populares a través del ocio y el consumo, tienen mucha relevancia en este momento, pues no solo se trataría de proceder a la asimilación de los valores neoliberales, sino también a la eliminación de las referencias de clase y por tanto a la finalización del conflicto social, hecho que sin duda habría sido perseguido en la transformación de las estructuras económicas y que dan muestra de una estructura espacial de las relaciones derivadas de la concepción del espacio. Esta incorporación requiere de un espacio propio, de un lugar donde reflejar el igualitarismo dominante, donde las relaciones de clase queden ocultas, atenuadas cuanto menos. Parece lógico pensar que este lugar, este espacio de representación de la nueva sociedad de consumo, sea el centro urbano, y en el caso de Madrid, estos rasgos parecen observarse con mayor claridad en el ámbito de la Almendra Central.

\section{Transformaciones morfológicas de la Almendra Central}

El análisis de las estructuras de acumulación de capital que hemos visto hasta ahora, nos facilita suficiente información como para comprobar la intensificación de la diferenciación del espacio llevada a cabo en la fase de expansión neoliberal, como muestra de la reorganización espacial que se ha derivado de la misma. Sin embargo, aún nos resulta insuficiente para evaluar los cambios morfológicos producidos y la relación espacial de los mismos. La segregación de clase a la que apunta el modelo parece estar vinculada con la transformación de las formas de vida, por lo que vamos a ir introduciendo algunos aspectos relacionados con la conceptualización fetichista del espacio. En el intercambio inmobiliario, el valor se podría relacionar con unas cualidades naturales del propio inmueble, pero también debemos considerar la influencia de la relación social de los productos inmobiliarios, sustentada, a nuestro modo de ver, en la representación que juega el espacio dentro de la actual sociedad de clases. Si a lo largo de la historia de las ciudades, éstas han reflejado y han sido el reflejo de las diferentes clases que en ella se asentaban, durante la fase neoliberal se ha llevado a cabo una expansión simbólica para penetrar con ello en el espacio vivido por las capas populares, dando muestras de su capacidad de dominación, a través de la apropiación simbólica de espacios histórica y morfológicamente heterogéneos.

Llegados a este punto, y tal y como habíamos planteado más arriba, este proceso ha sido posible con la ayuda de la desregulación urbanística y el desmantelamiento

54 Harvey, 2014

55 Garnier, 2015 
de los instrumentos de planificación llevado a cabo desde la aprobación del Plan General de 1997, punto de arranque de un proceso de re-escalamiento en la planificación madrileña que cedía su capacidad de regulación al mercado financiero y del suelo. En este contexto, la planificación desaparece dando lugar a una redefinición del espacio central a partir de la combinación de factores de acumulación, tal y como hemos visto en el epígrafe anterior. Es así como la planificación pierde su sentido de instrumento de cohesión social, otorgado por la urbanística bajo el modelo fordista de producción y roto durante el proceso de globalización llevado a cabo desde los años 1990.

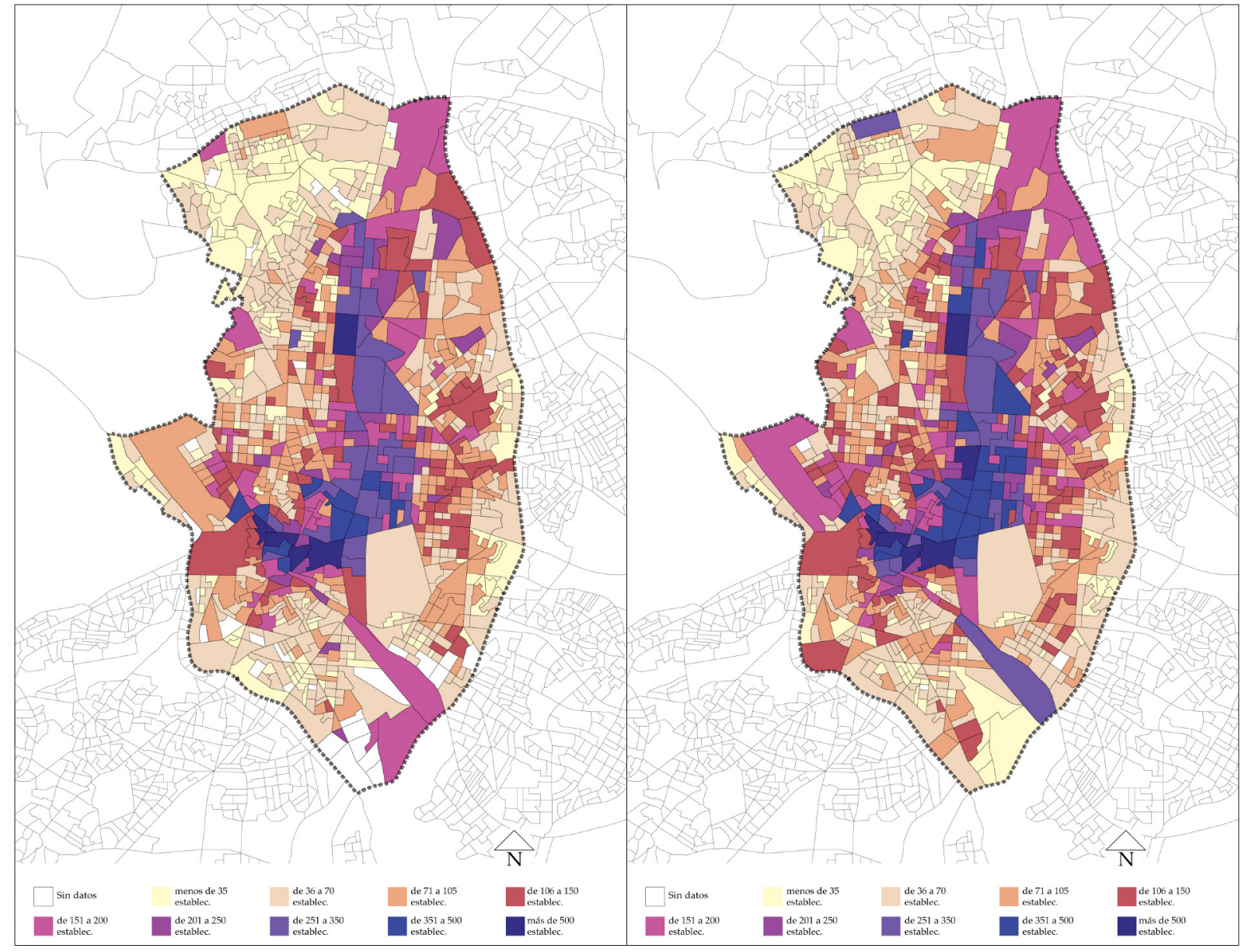

Figura 3. Acumulación de locales con actividad económica en el año 1998 (izq.) y 2007 (dcha.). Fuente: Elaboración propia a partir de los datos del Instituto de Estadística de la Comunidad de Madrid

En este sentido, el espacio intervendría como mediador en el sentimiento de pertenencia y en la identificación de los individuos dentro de un sector social. Por tanto, el carácter representativo y simbólico del espacio vendría a determinar en gran medida el valor de los inmuebles y del suelo en el que se asientan. Este hecho, aparentemente obvio, supone reproducir las relaciones de poder en el ámbito urbano, lo que hace trasladar a la ciudad el sistema de dominación resultante del modo de producción neoliberal.

Existen múltiples rasgos que caracterizan las relaciones de poder en la ciudad actual, pero entre nuestros objetivos están el valorar las influencias del uso de es- 
pacio como expresión de las relaciones entre las diferentes clases sociales. Así, las actividades económicas pueden entenderse como la estructura de una relación de poder dada en la ciudad, siguiendo la lógica de la redefinición de los poderes contenida en los planteamientos de Brenner y Smith. Para ello, nos fijaremos en el tipo de actividad que se implanta en los diferentes ámbitos del centro urbano, por cuanto su número [ver Figura 3] y, sobre todo características [ver Figura 4], nos dan idea del proceso evolutivo realizado no solo en cuanto a las condiciones de la economía urbana, sino también en cuanto a la configuración del espacio. Esta idea nos la sugiere el hecho de que la estructura social o de clases tiende a producir el espacio que domina, transformándolo para producir los signos que dan identidad a los valores por ella representados 5657 , por lo que el tipo de actividad nos da una idea del objeto social que la determina.

El número de actividades lo podemos poner en relación con el re-escalamiento del sistema, puesto que las remodelaciones llevadas a cabo en el centro urbano serían parte de la lógica de destrucción creativa bajo una solución por infraestructuras, y quedarían sometidas a la mercantilización del espacio, desplazando por tanto las actividades de reproducción social hacia la periferia y alojando en el centro actividades de reproducción de capital.

El análisis de la acumulación de actividades nos muestra, nuevamente, el reforzamiento del eje Norte-Sur en cuanto al número de establecimientos que se fijan a lo largo de las dos últimas décadas, mientras que en el resto de la Almendra Central se aprecia una disminución o incluso estancamiento del número de establecimientos con actividad económica asociada. Esto podría estar vinculado con el grado de especialización espacial, puesto que la economía madrileña ha tendido a una financiarización tal que ha hecho que vayan desapareciendo las actividades productivas como la industria, instaladas tradicionalmente en zonas populares del norte y del sur de la Almendra Central. Aunque en estos ámbitos se siguen alojando pequeñas industrias de servicio (talleres mecánicos, ebanisterías, comercios relacionados con la automoción e incluso talleres artesanales) - seguramente como reflejo de antiguas formas de vida-, hay una tendencia a no ocupar este tipo de locales, lo que supondría una reducción del número de establecimientos. Igualmente, la financiarización espacial supone alojar en los espacios propios de la burguesía nuevas unidades económicas para la gestión del sistema de acumulación, desplazando con ello a los sectores más débiles y depurando aún más la estructura morfológica de estos ámbitos..

56 Las actividades económicas debemos vincularlas a la producción de capital visto anteriormente, pero también tiene una relación morfológica, por cuanto el tipo de actividad sirve a una determinada estructura social. Este hecho lo observamos claramente en el análisis de Baker sobre la gran Vía, pero también en el propio Plan Especial de Revitalización del Centro Urbano (PERCU) se intuye una cierta dependencia al intentar «proteger» la diversidad de actividades, especialmente aquellas más tradicionales como la artesanía o cierto tipo de comercio y establecimientos de ocio.

57 Baker, 2009

58 Oficina Centro, 2004 
Por otro lado, las importantes renovaciones urbanas producidas en estos ámbitos han hecho que se destruyan parte de los establecimientos ${ }^{59}$, para proceder a remodelaciones residenciales siguiendo una lógica de destrucción creativa con la que proseguir la incesante dinámica de producciónacumulación. Así es como las nuevas formas y la morfología urbana resultantes difieren considerablemente de la original, llevando a la destrucción de la estructura social que daba sustento a la estructura económica.

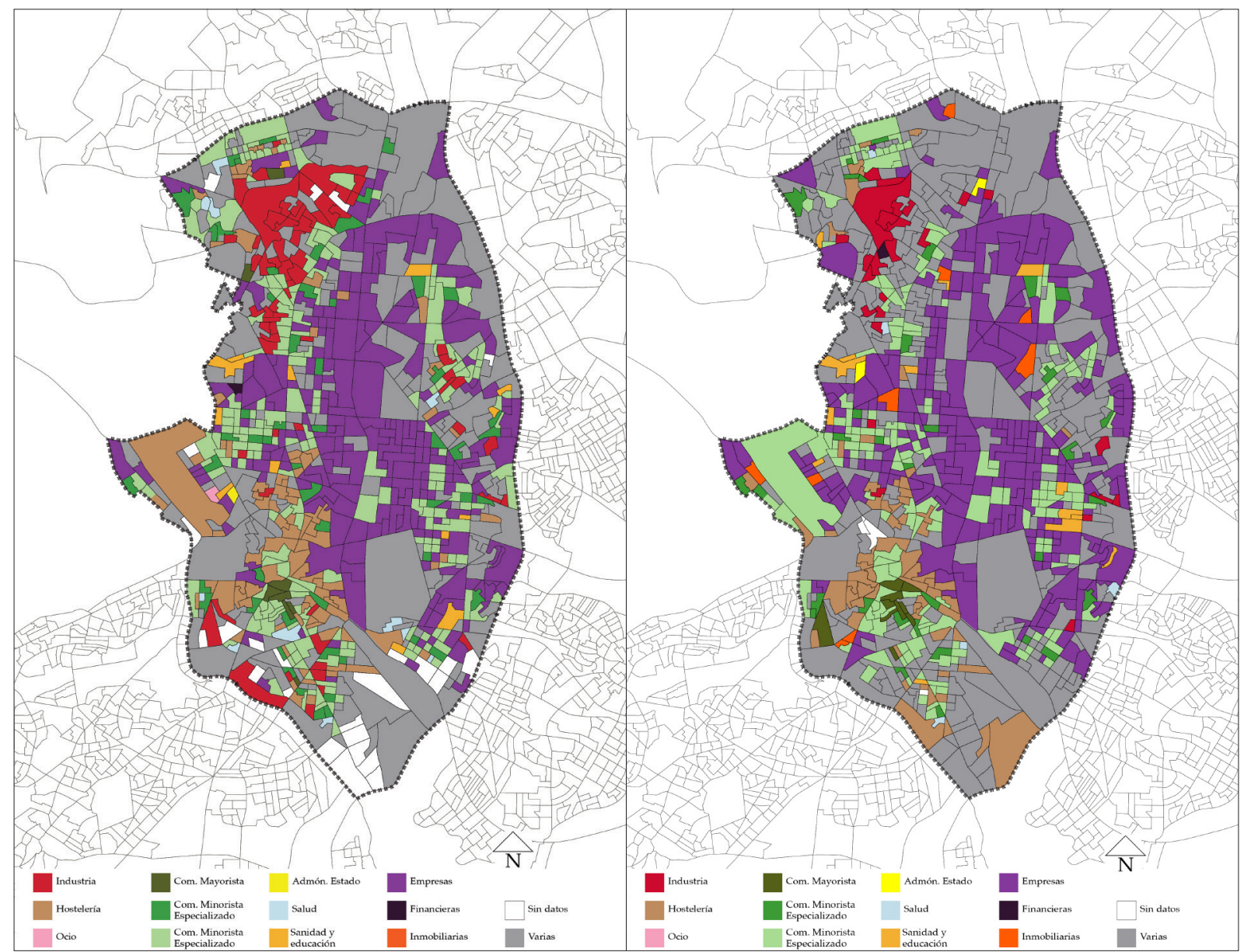

Figura 4: Acumulación de actividades dominantes en el año 1998 (izq.) y 2007 (dcha.).

Fuente: Elaboración propia a partir de los datos del Instituto de Estadística de la Comunidad de Madrid

El uso del espacio nos daría muestras de la relevancia del espacio en la transformación neoliberal, y el número de establecimientos sería un factor más de la intensidad competitiva llevada a cabo en el re-escalamiento de la estructura capitalista. Esto llevaría consigo la redefinición del papel de los espacios centrales, también la tradicional contradicción centro-periferia, aumentando las diferencias entre el espacio vivido y el producido, intensificando la producción de un espacio diferenciado cada vez más vinculado a la mercancía y la monetarización, como muestra la localización de actividades en Madrid.

La fragmentación que se observa en la acumulación de actividades dominantes (ver Figura 4) parece responder a la especialización económica en los términos

59 Morcillo, 2014 
anteriormente explicados, de tal manera que la intensificación de las actividades financieras, inmobiliarias y empresariales, en general, apuntan a la diferenciación espacial que se requeriría para la dirección y gestión del sistema de acumulación. Según el sistema desarrollado por Brenner ${ }^{60}$, Madrid estaría convirtiéndose en un centro de gestión del capitalismo nacional, pero aún estaría lejos de ser un centro de gestión global, situación a la que han aspirado los planificadores y gestores de la ciudad y para la que han movilizado gran cantidad de recursos colectivos. Volvemos a apreciar el reforzamiento del eje NorteSur como espacio estructurante de la centralidad, acumulando en torno suyo las principales actividades de gestión del sistema de acumulación, mientras que las actividades de ocio y comercio tienden a concentrarse en los lugares históricos, en un proceso, no ya de gentrification, sino fundamentalmente de depuración del modelo diferenciado, resaltando con ello una reasignación simbólica del espacio y cediendo gran parte de los códigos de interpretación a los sectores sociales más avanzados. Esta elitización espacial también queda apuntada por la expansión en la Almendra Central de las actividades relacionadas con la ilusión de ascenso - fundamentalmente aquellas vinculadas con la salud o la imagen del cuerpo-, y aunque no llegan a ser dominantes, su expansión es significativa en estas décadas.

El cambio en la estructura de actividades ha llevado pareja la destrucción de formas urbanas preexistentes, en una lógica de destrucción creativa del espacio, facilitadas por una importante movilización de inversiones públicas. Estas se han dado especialmente en infraestructuras ligadas con la movilidad y la imagen de la ciudad [ver Figura 5], pero también en la imagen simbólica del centro ${ }^{61}$. De esta manera, la movilización de plusvalías colectivas ha sido utilizada como mecanismo de reproducción de rentas privadas, a través de mecanismos de crédito y endeudamiento a largo plazo asumidos principalmente por el Ayuntamiento de Madrid, forma depurada de la acumulación por desposesión a la que nos hemos referido anteriormente y que constata la transmisión de rentas de trabajo a rentas del capital ${ }^{62}$. Paralelamente se han desarrollado numerosas figuras financieras e inmobiliarias que han facilitado la permuta de inmuebles entre diferentes administraciones o la aprobación de convenios urbanísticos de desarrollo privado de ámbitos de gestión públicos, sendos símbolos del trasvase de las plusvalías colectivas a las rentas privadas. En cualquier caso, se ha producido un hecho significativo en Madrid y es que la importante movilización de recursos públicos ha sido utilizada con el objetivo de

60 Brenner, 2003

61 Morcillo, 2015

62 Es importante señalar que las actuales cifras de deuda pública sitúan a Madrid a la cabeza de las ciudades más endeudadas del país en valores absolutos con cifras de 6.105 millones $€$ en el año 2011, reducida hasta los 4.766 millones € en el año 2015, aunque su posición en valores de deuda/ habitante la sitúan en posiciones inferiores con un nivel de endeudamiento de $2.194 €$ /habitante en 2011 y $1.517 € /$ habitante en 2015. En lo que a la investigación se refiere, esta deuda ha permitido una importante transformación urbana con la casi exclusiva inversión pública, no equiparable a ningún otro momento de la historia reciente de la ciudad, incluidas las grandes transformaciones sufridas en los años ochenta, una vez retornada la democracia al país. 
producir una transformación urbana de la centralidad. Por su parte, la aportación de capital privado ha sido escasa, más aún si lo comparamos con la llevada a cabo en la urbanización de la periferia, donde las rentas privadas han conseguido importantes plusvalías en torno al mercado del suelo y la vivienda, cosa difícil de conseguir en el centro urbano.

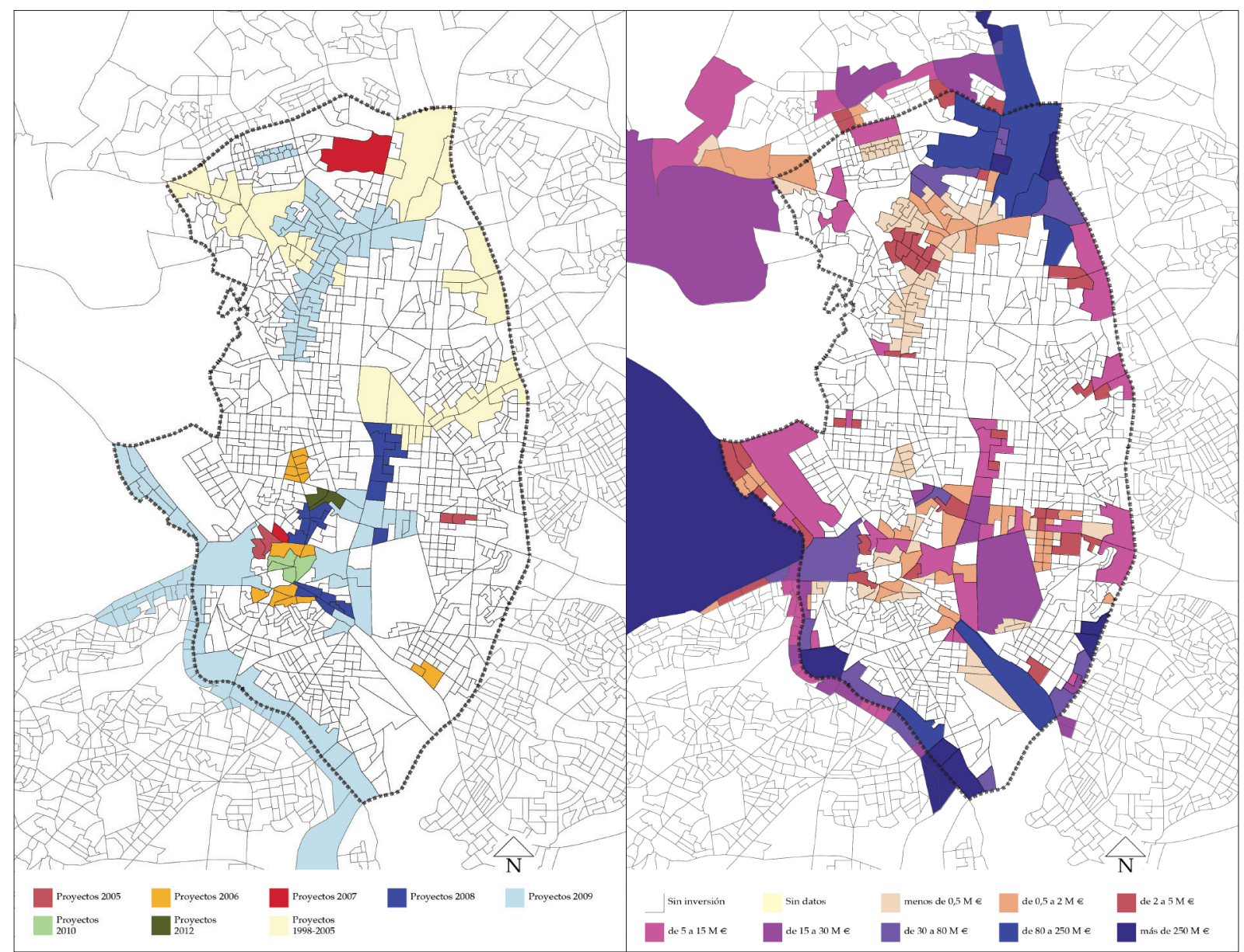

Figura 5: Proyectos realizados (izq.) e inversión en infraestructuras (dcha.) en el centro de Madrid entre los años 1998 y 2011.

Fuente: Elaboración propia a partir de los datos del Ayuntamiento de Madrid.

La combinación de las geografías de acumulación de actividad y de plusvalías colectivas nos vuelve a mostrar el reforzamiento de los principales ejes vinculados a la representación social del neoliberalismo, depurando aún más, el modelo de acumulación y la estructura morfológica de la Almendra Central. Espacios de mayor inversión pública llevan parejos espacios de mayor transformación en la estructura de actividad, demostrado no solo por tal cambio de usos, sino también por la producción de capital medida en términos de PIB.

Las geografías de acumulación de los diferentes tipos de capital que hemos visto, nos reflejan unas formas de acumulación que parecen seguir unos patrones similares. Las formas en mosaico que se adoptan, sugieren que en el centro de Madrid se llevaría a cabo la competencia de unos espacios con otros por atraer inversiones, reproducir capital y depurar la estructura morfológica resultante. Las inversiones 
producidas parecen indicar el reforzamiento de los valores culturales y las formas de vida dominantes, de tal suerte que el mosaico podría ocultar una forma depurada de coerción sobre los sectores más débiles, condicionando las características socioespaciales que regulan, en definitiva, la localización de la población. Las formas resultantes son, a nuestro modo de ver, indicativas de una segregación social que determinan el esfuerzo desigual de cada clase social para apropiarse del espacio. Es así que el mosaico observado en las geografías de acumulación puede interpretarse como la heterogeneidad competitiva a la que hace alusión Harvey, más que a la capacidad de resistencia frente al modelo neoliberal, aspecto que podríamos deducir del planteamiento de Brenner en cuanto a las nuevas espacialidades derivadas de la confrontación social. Esta idea también estaría presente en Sevilla ${ }^{63}$ cuando nos sugiere que la reorganización del capitalismo y el re-escalamiento del Estado, daría pie a nuevas espacialidades donde sería posible la confrontación social y la re-apropiación simbólica de espacios mercantilizados. Sin embargo, las operaciones comerciales más recientes ${ }^{64}$ que han encontrado en el centro urbano un buen acomodo, parecen indicarnos que se trata más de lo primero que de lo segundo, y que por tanto estas formas de resistencia y de reapropiación simbólica entrar.

\section{La resistencia al modelo}

El desarrollo de la solución de la expansión neoliberal no parece, a tenor de lo visto, el resultado de un acuerdo social, y por ello en los últimos tiempos ha surgido una tendencia a la resistencia a este modelo de producción de espacio que, a nuestro entender, deja entrever los conflictos de clase ocultos por la ilusión del ascenso social, y que tenderían a apropiarse de un espacio que el neoliberalismo no ha sido capaz de dominar con plenitud.

El modelo de producción de espacio se sostendría por una lógica de monetarización, cuyas expresiones serían tanto los precios inmobiliarios como el tipo de actividad económica desarrollada. Esto conduciría, como hemos dicho, a una coerción asimilada, consecuencia de la competencia entre individuos, y que el neoliberalismo enmascara bajo la expresión del "fin del conflicto social" que dará lugar al nacimiento de una nueva sociedad de individuos en "libre" competencia entre ellos. Esta podría ser una de las consecuencias del paulatino desmantelamiento de servicios educativos, sanitarios y culturales - en rigor convertidos ya en la aspiración de estatus de los individuos lo que hasta hace bien poco eran elementos de reproducción social-.

La cohesión y equilibrio social se esfumarían en este proceso en el que la competencia desigual, no solo en función de renta, sino incluso en términos culturales y simbólicos, se completaría en un espacio segmentado, donde el esfuerzo por alcanzar el estatus y la posición social deseada no se realiza por igual, sino que corresponde a los rangos más bajos de la escala la tarea de sostener un sistema financiero que

63 Sevilla, 2012

64 Morcillo, 2017 
se vuelve sistemáticamente en contra, precisamente, de quienes mayores esfuerzos tomaron en una pugna por el reconocimiento social adquirido.

En esencia, el espacio complementaría la función de otorgar valor simbólico a la posición social, en un proceso de invisibilización ${ }^{65}$ no ya de las relaciones sociales de producción, sino de las mismas clases sociales, relegando a las clases populares a su ocultamiento. Esto supondría la expulsión de una gran mayoría de individuos no del espacio físico vivido, sino del mismo espacio habitado, negándoles la capacidad de producción espacial al tiempo que es absorbida su fuerza de trabajo. Pese a ello, numerosos autores sostienen que las nuevas condiciones de producción espacial permiten la producción de nuevas espacialidades allí donde el neoliberalismo aún no ha encontrado el suficiente nivel de beneficios o en aquellos ámbitos donde la intensificación de la desigualdad - económica, social o urbana- le hace abandonar.

Esta realidad de asignación de valor se refleja en la ilusión de la posición social alcanzada a partir de la adquisición en propiedad de una vivienda, lo que ha resultado el ahogo de amplios sectores sociales, cuyo esfuerzo pone de manifiesto la intención neoliberal por extraer beneficios a partir del endeudamiento de los asalariados, grandes nichos de capital con los que el sistema financiero internacional ha podido financiarse sin necesidad de recurrir a la producción material para intensificar sus beneficios.

Paradójicamente, la sutil capacidad de control neoliberal ha supuesto que el incremento de los conflictos urbanos, originados por la reestructuración de la ciudad capitalista en cuanto al tejido político, económico y social hayan quedado camuflados. El espacio parece haberse convertido en una de esas sutiles expresiones de la coerción, como reflejo de la aspiración de los individuos por alcanzar el estatus anhelado, ya sea por la adquisición de la vivienda, ya sea por compartir el lugar con individuos de otro rango y posición superiores. Esto ha dado lugar a una competencia entre individuos, y de alguna manera entre espacios, que daría como resultado una producción espacial heterogénea para dar muestras de acceso universal, pero donde la apropiación del mismo se realiza por la capacidad de consumo y por la capacidad de interpretar el valor simbólico del mismo.

Para atemperar este dominio, han surgido una significativa cantidad de movimientos urbanos de apropiación del espacio y que deben gran parte de sus referencias al movimiento 15M en España, cuya eclosión en 2011, supuso una reinterpretación espacial, por cuanto el uso de espacios simbólicos abrió un camino hacia lo que parecía una conquista del espacio neoliberal ${ }^{66}$. Sin embargo, este movimiento y sus réplicas en torno a la resistencia urbana, tal y como sugieren autores como Sanz $^{67}$ o Garnier ${ }^{68}$ adolecen aún del sentido emancipador por cuanto la ocupación de espacio no interfiere en la capacidad de acumulación de capital ni en la dinámica neoliberal de transformación del espacio.

65 Garnier, 2015

66 Sevilla, 2015

67 Sanz, 2012

68 Garnier, 2012 
Esto nos mostraría que hay niveles diferentes de apropiación de la ciudad y de los valores económicos, simbólicos y sociales que identifican a unos grupos con su entorno. El cambio de los mecanismos de reproducción social no parece que sea el objetivo de numerosos de estos grupos y movimientos sociales, pese a que su actividad y activismo tienen sus límites dentro de este campo, lo que parece conducirnos a una cierta reproducción de valores que no cuestionan el papel que las relaciones de producción juegan en la reproducción social. Estos movimientos serían la consecuencia del reescalamiento de la ciudad que sostiene Brenner, pero también significaría, tal y como ya hemos dicho, la aparición de nuevas formas de asimilación que no confrontarían con la capacidad de producción simbólica del neoliberalismo, sino que se adaptarían a las formas neoliberales de producción del espacio para reasignar los valores dominantes bajo una ilusión de resistencia o transformación.

Pese a todo, algunos ámbitos parecen reflejar una cierta resistencia urbana, apoyándose para ello en la heterogeneidad propia de formas de vida anteriores al neoliberalismo y que seguramente resisten a base de las características de la población residente o de la estructura de propiedad aún vigente.

Si la ciudad keynesiana ${ }^{69} 70$, fundamentada en el fordismo y la sociedad salarial como formas de producción y reproducción social, respectivamente, se caracterizaba por ser el lugar del consenso social, donde la reproducción social quedaba supeditada al trabajo y la división técnica del mismo era origen de la división en clases, la ciudad neoliberal bascula hacia la reproducción de capital y emprende para ello una transformación urbana que no obstaculice dicho proceso. En este, las unidades diferenciadas que apreciamos distorsionando la homogeneidad de las formas de acumulación podrían resultar formas de resistencia, si en ellas, o a partir de ellas, se organizaran respuestas y discursos que alteraran de alguna manera la implacable expansión neoliberal, produciendo un discurso urbano emancipatorio y origen de diferentes formas de vida no sustentadas por tanto, en la posición y ascenso social como principal y casi único argumento de sociabilidad.

\section{Consideraciones finales}

A lo largo de los últimos años, de hecho casi una década ya, parece haberse consolidado la idea de que la planificación urbana y el modelo de ciudad producido habían entrado en crisis, al calor de la quiebra financieroinmobiliaria de 2009. Es sin duda un punto de vista razonable, pero no conviene que dejemos a un lado la posibilidad de que esta crisis haya puesto en evidencia el cambio del modelo que se había estado produciendo durante la expansión neoliberal y por tanto, en los años preceden-

69 Utilizamos en este punto la expresión empleada por Neil Smith, por cuanto la gran operación del capitalismo por conseguir grandes consensos sociales a partir de la determinación de la clase media como sujeto principal de la nueva sociedad, tiene su apoyo en las medidas propuestas y en gran parte desarrolladas por John Maynard Keynes tras la II Guerra Mundial y que permitió la consolidación del Bienestar en Europa a partir de los años 1950 hasta la implosión de las teorías neoliberales en los años 1980.

70 Smith, 2005 
tes a la crisis. Los datos que hemos ido mostrando hasta el momento, nos sugieren esta posibilidad, y por tanto, no sería descabellado pensar en la influencia urbana en la configuración de nuevas relaciones de producción que soporten los procesos de acumulación de capital.

Aunque aún no parece estar conformado definitivamente, parece atisbarse un nuevo modelo de producción espacial inserto en el cambio de relaciones de producción. Este se fundamentaría en la competencia espacial, siguiendo la lógica neoliberal de competencia entre organizaciones capitalistas e, incluso, entre individuos. La lógica competitiva, trasladada al ámbito urbano se traduciría en un desigual reparto de las inversiones, de tal suerte que aquellos lugares con mayor capacidad de acumulación de capital, serían los que atrajeran las inversiones públicas y privadas, garantizando con ello una reproducción de capital que aspira a ser continua e ilimitada, aún y pese a la crisis financieroinmobiliaria.

En el caso de Madrid, y tal y como hemos estado viendo, una de las pruebas más evidentes de esta competencia espacial es el reforzamiento del eje central como espacio para la producción de capital y la acumulación de las mayores rentas inmobiliarias. Este eje representaría no solo las nuevas relaciones de producción espacial, sino que el hecho de que en su entorno se concentre la acumulación de capital simbólico facilita la expansión de valores neoliberales hacia el resto de la Almendra Central. Esta importante presencia del eje central en los procesos de acumulación de capital, puede estar suponiendo que la expansión de las características de centralidad que se observan en el conjunto de la Almendra Central, sean los derivados de la posición de clase dominante. Estos elementos requerirían de un estudio más minucioso que en este trabajo no hemos emprendido, pero en cualquiera de los casos convenía, al menos, apuntarlos.

Sin embargo, a lo largo del trabajo hemos ido apuntando datos que parecen apuntar a una competencia entre lugares, algo que se ha manifestado esencialmente en una disputa por la acumulación de inversiones entre los diferentes ámbitos del centro urbano. Esta dinámica parece haber dejado como resultado una reducción de lo urbano y la depuración de un modelo espacial fragmentado, especializado y diferenciado, manifestado esencialmente en la elitización del centro urbano. Este, en función de los nuevos paradigmas del modelo, se ha ido convirtiendo en el símbolo del nuevo marco relacional del neoliberalismo, adoptando el consumo y el ocio como casi las únicas referencias socioespaciales, expresión contemporánea de las históricas relaciones de clase. En esencia, la mística de este espacio central, y por tanto su poder, parece establecerse en torno al consumo de mercancías y ocio, asignando al lugar un papel representativo de la posición de clase del individuo, pero también capaz de determinar los mecanismos de reproducción. De esta manera, la morfología social del lugar quedaría ligada a su capacidad por reproducir capital ya sea económico, social o simbólico- con lo que se reducen los espacios de reproducción social históricamente construidos. 
Este modelo de producción espacial, consolidado durante la expansión neoliberal, no parece haber dado muestras de debilitamiento pese a la evidente ralentización inversora producida tras la crisis de 2009. Incluso, se han producido expresiones de resistencia, que explosionaron fundamentalmente tras la aparición del 15M en 2011, pero que aún parecen estar lejos de ser formas emancipadoras y de rebelión que supongan un cambio en la producción espacial.

En este sentido, hemos podido observar cómo las formas en mosaico favorecerían la aparición de unidades de resistencia espacial, de tal manera que la heterogeneidad del modelo no solo reflejaría la competencia espacial, sino también la capacidad de resistencia que tendrían algunas unidades del mosaico, evitando son ello la expansión de los valores y formas urbanas neoliberales. El mosaico morfológico y formal de la Almendra Central habría podido facilitar la explosión de los movimientos de resistencia, pues parecen ser más numerosos y sólidos en las zonas centrales de la ciudad. Esta vinculación entre el mosaico urbano y los movimientos de resistencia surgidos es una muestra del cambio dado en las referencias socioespaciales, no solo de la centralidad, sino del conjunto urbano. Estas se manifestarían esencialmente en relación a las formas colectivas de uso del espacio, pero aún no han sido capaces de manifestar cambios sustanciales en cuanto a las relaciones entre uso espacial y producción de capital, o entre las relaciones sociales determinadas por el uso de los lugares de centralidad. De hecho, el 15M supone un cambio en la producción del uso del espacio de centralidad, pero hoy en día sus consecuencias han reproducido, de alguna manera, un esquema simbólico donde la ciudad y los individuos, se reflejan en el espacio simbólico central, excluyendo con ello la posibilidad de transformación de las relaciones de competencia centroperiferia o incluso los cambios representativos del uso de la centralidad que vayan más allá del intercambio de mercancías o la reproducción de capital.

\section{Bibliografía}

AGLIETTA, Michel. El capitalismo en el cambio de siglo: la teoría de la regulación y el desafío del cambio social. New Left Review, 2001, nº 7, pp. 16-70.

ARRIGHI, Giovanni. El largo siglo XX. Madrid: Akal, 1999, 2014 (2ª edición).

ARRIGHI, Giovanni. Adam Smith en Pekin. Orígenes y fundamentos del siglo XXI. Madrid: Akal, 2007

BAKER, Edward. Madrid cosmopolita. La Gran Via, 1910-1936, Madrid: 2009.

BRENNER, Neil. Tesis sobre la urbanización planetaria, Nueva Sociedad, 2013, nº 243. BRENNER, Neil. La formación de la ciudad globalizada y el re-escalamiento del espacio del Estado en la Europa Occidental post-fordista, EURE (Santiago), 2003, vol. 29, n 86, doi: http://dx.doi.org/10.4067/S0250-71612003008600001.

BRENNER, Neil; PECK, Jamie; THEODORE, Nick. Neoliberal Urbanism: Models, Moments, Mutations, SAIS Review, 2009, vol. XXIX, $\mathrm{n}^{0} 1$.

CAMPOS VENUTI, Giuseppe. Urbanismo y austeridad, Madrid: Siglo XXI editores, 1981, 1ª edición. 
FERNÁNDEZ DURÁN, Ramón. El Tsunami urbanizador español y mundial. Barcelona: Virus, 2006.

FERNÁNDEZ RAMÍREZ, Cristina \& ROCH PEÑA, Fernando. La quiebra de la ciudad global y sus efectos en la morfología urbana. Madrid, bajo la lógica inmobiliaria de la acumulación-desposesión. Urban, 2012, nº NS03, pp. 45-63.

GARNIER, Jean-Pierre. La invisibilización urbana de las clases populares, en PAPELES de relaciones ecosociales y cambio global, 2015, no 130, pp. 29-45.

GARNIER, Jean-Pierre. Salir a la calle ¿para qué y con quien?» disponible en linea en: <http://multipliciudades.org/2012/11/18/jean-pierre-garnier-salir-a-la-callepara-que-y-con-quien/> [última consulta: diciembre 2012].

HARVEY, David. Diecisiete contradicciones y el fin del capitalismo, Quito: Instituto de Altos Estudios Nacionales del Ecuador, 2014, $1^{\text {a }}$ edición.

HARVEY, David. Ciudades Rebeldes. Del derecho de la ciudad a la revolución urbana, Madrid: Akal, 2013, 1 a edición.

HARVEY, David. Espacios del capital. Hacia una geografía crítica, Madrid:Ediciones Akal, 2007.

HARVEY, David. The limits to capital, Oxford: Basil Blackwell, 1982.

LEFEBVRE, Henry. La producción del espacio, $1^{\text {st }}$ edition, Alcobendas: Capitán Swing, 2013.

LEFEBVRE, Henry. El derecho a la ciudad, Barcelona: Ediciones Península, 1969.

LACALLE, Daniel. La clase obrera en España. Madrid: El Viejo Topo / Fundación de Investigaciones Marxistas, 2006.

MARX, Karl \& ENGELS, Friedrich. El manifiesto comunista. Torrejón de Ardoz (Madrid): Nórdica Libros, 2012.

MORCILLO ÁLVAREZ, Daniel. La imagen en el cuerpo urbano. La transformación de Madrid hacia el consumo, Urbano, 2017, no 35, mayo, pp. 32-43. Doi: https://doi. org/10.22320/07813607.2017.20.35.03

MORCILLO ÁLVAREZ, Daniel. Inversión, infraestructuras e imagen en la producción del espacio de centralidad en Madrid.Ciudades, 2015, n 18, Instituto Universitario de Urbanística de la Universidad de Valladolid, pp. 163-181.

MORCILlO ÁLVAREZ, Daniel. La Almendra Central de Madrid, espacio de normalización social. XIII Coloquio Internacional de Geocrítica: El control del espacio y los espacios de control. Barcelona: Universidad de Barcelona, 2014. Disponible en línea: <http://www.ub.edu/geocrit/xiii-coloquio/xiii-coloquioportada.htm> [última consulta: diciembre 2015]

OBSERVATORIO METROPOLITANO. La crisis que viene, Madrid: Traficantes de sueños, 2011.

OFICINA CENTRO. ÁREA DE GOBIERNO DE URBANISMO, VIVIENDA E INFRAESTRUCTURAS. Plan Especial de Revitalización del Centro Urbano. Madrid: 2004, Ayuntamiento de Madrid,. 
OYARZÁBAL DE MIGUEL, Javier (coord.). Ranking de ciudades europeas 2011. Barómetro de economía de la ciudad de Madrid, 2012, n 31, Ayuntamiento de Madrid, pp. $111-126$.

RAMOS GALLARÍN, Ana (coord.). Ranking de ciudades europeas 2012. Barómetro de Economía de la ciudad de Madrid, 2013, n 35, Ayuntamiento de Madrid, pp. 85-99.

ROCH PEÑA, Fernando. Revolución neoliberal y "utopía" ciudadana, una batalla inaplazable. Ciudades, 2015, $\mathrm{n}^{\circ}$ 18, Instituto Universitario de Urbanística de la Universidad de Valladolid, pp. 49-68.

ROCH PEÑA, Fernando. La deriva patológica del espacio social en el modelo inmobiliario neoliberal madrileño. X Coloquio Internacional de Geocrítica, 2008, Universidad de Barcelona, Barcelona. Disponible en línea: <http://www.ub.edu/ geocrit/sn/sn-270/sn-270-40.htm> [última consulta: diciembre 2015]

de SANTIAGO RODRÍGUEZ, Eduardo. Una lectura de las políticas de suelo y los modelos urbanísticos madrileños desde mediados de los años 1990: de la liberalización a la resaca inmobiliaria, Geopolitica(s). Revista de estudios sobre espacio y poder, 2012, vol. 3, $\mathrm{n}^{\circ} 1$, pp. 83-116.

SANZ ARRANZ, Juan Ramón. Carta a Hessel. Madrid: Fundación Domingo Malagón, 2012.

SEVILLA BUITRAGO, Álvaro. Espacialidades indignadas: la producción del espacio público en la \#spanishrevolution. ACME: An International e-journal for critical geographies, 2015, vol. 14, $\mathrm{n}^{0} 1$, pp. 90-103.

SEVILLA BUITRAGO, Álvaro Urbanismo y reproducción social. Una introducción a su historia, Cuadernos de investigación urbanística, 2012, Enero-febrero.

SMITH, Neil. El redimensionamiento de las ciudades: la globalización y el urbanismo neoliberal. En SMITH, N. \& HARVEY, D. Capital financiero, propiedad inmobiliaria y cultura. Barcelona: Contratextos, 2005.

VAROUFAKIS, Yanis. El minotauro global: Estados Unidos, Europa y el futuro de la economía mundial. Madrid: Capitán Swing, 2013.

YNZENGA, Bernardo. (ed.). Ideas y estrategias para Madrid centro, Madrid: Fundación COAM, 2005.

(c) Copyright: Daniel Morcillo Álvarez, 2017

(c) Copyright: Scripta Nova, 2017.

Ficha bibliográfica:

MORCILLO ÁLVAREZ, Daniel. Producción de espacio en la expansión neoliberal en Madrid. Scripta Nova. Revista Electrónica de Geografía y Ciencias Sociales. Barcelona: Universitat de Barcelona, 15 de septiembre de 2017, vol. XXI, $n^{\circ}$ 573. [ISSN: 1138-9788] 